\title{
Health-Related Quality of life in Students of an Education Institution of Ventanilla
}

\author{
Lucia Silva-Bueno $^{1}$, Brian Meneses-Claudio ${ }^{2}$, Hernan Matta-Solis $^{1, *}$, Lourdes Matta-Zamudio $^{1}$ \\ ${ }^{1}$ Faculty of Health Sciences, Universidad de Ciencias y Humanidades, 15314, Lima-Perú \\ ${ }^{2}$ Image Processing Research Laboratory (INTI-Lab), Universidad de Ciencias y Humanidades, 15314, Lima-Perú
}

\begin{tabular}{l} 
A R T I C L E I N F O \\
\hline Article history: \\
Received: 03 August, 2020 \\
Accepted: 28 September, 2020 \\
Online: 20 October, 2020
\end{tabular}

Keywords:

Adolescents

Quality of life

Students

Health

Adolescent psychology

\begin{abstract}
A B S T R A C T
The Health-related quality of life corresponds to the perception that people have of their level of well-being, considering aspects of their lives and their impact on their state of health. The studies were initially carried out in a population that presented both acute and chronic pathologies and covered practically all areas of medical specialties; subsequently, the interest focused on studying health-related quality of life in the general population and then in the population of children and adolescents. That is why, in this research work, the evaluation of the adolescent to prevent future problems was raised; to carry out the evaluation, the questionnaire called KIDSCREEN 52 was used, which consists of 52 closed questions divided into 10 dimensions, providing an idea of how the adolescent feels. The following results were obtained: The Health-related quality of life in adolescents of an Educational Institution of Ventanilla, where 430 students representing 59.1\% have high quality of life and 298 students representing 40.9\% have medium quality of life; according to its dimensions, adolescents from the Educational Institution of Ventanilla, its most affected dimension was economic resources, with 64 students representing $8.8 \%$ having a low level. In the relationship with parents' dimension, it appreciates that $3.4 \%$ of students do not have a good family atmosphere since they do not live with their parents, but with uncles and/or grandparents.
\end{abstract}

\section{Introduction}

Health-related quality of life (HRQL) defined as "individual and group perceived physical and mental health". It has been used to evaluate medical care from the patient's point of view and as a subjective indicator of social well-being [1]. It corresponds to the perception that people have of their level of subjective well-being, considering various aspects of their lives and their impact on their state of health. Studies in HRQL were initially carried out in a population that presented both acute and chronic pathologies and covered practically all areas of medical specialties; subsequently, the interest was concentrated in studying HRQL in the general population and then in the population of children and adolescents. Currently, studies in school children and adolescents have increased [2]. HRQL in childhood and adolescence is useful for describing the health of a population and establishing comparisons between subgroups with certain characteristics (for example, sociodemographic, regional, etc.). In pediatric clinical practice, the study of HRQL can facilitate knowledge of health status, study the

${ }^{*}$ Corresponding Author: Hernan Matta-Solis, Mr., +51 1999751065 \& hmatta@uch.edu.pe

www.astesj.com

https://dx.doi.org/10.25046/aj0505118 effect of different treatments, identify levels of morbidity and facilitate clinical decisions [3]. Adolescents are considered as individuals in constant development, that is why they need to grow in a balanced and healthy way within a safe and structured environment, in order to develop positively on a physical, educational, emotional and social level [4].

In the research work [5] in 2017, it was indicated that a total of 550 adolescents aged $16 \pm 1$ years completed the questionnaires. $39 \%$ consumed alcohol in the last month, 31\% smoked, 33\% used marijuana, and 33\% admitted using multiple drugs. High-risk alcohol consumption was associated with a lower perception of psychological well-being, self-perception, and the school environment. This last dimension was affected in those who admitted the use of marijuana during the last month. Multiple drug use (three substances) was associated with a lower perception of physical and psychological well-being, self-perception, relationship with parents, family life and the school environment; in conclusion, high-risk alcohol consumption and multiple drug use (three substances) have a negative impact on the HRQL of school-age adolescents. 
In [6] in 2019, the authors explain that of the 723 adolescents, $13 \%$ reported having been bullied; there were no gender differences within this finding. However, more boys than girls reported that they had bullied others. Both bullying and intimidation of others were associated with a lower HRQL; however, being bullied was associated with lower scores. Greater self-efficacy was associated with better HRQL. Self-efficacy contributed significantly to predicting variation in HRQL. In conclusion, being involved in bullying, as a victim or bully, is associated with a lower HRQL. The association between general self-efficacy and HRQL indicates that self-efficacy could be a resource to increase HRQL in adolescents. Their findings highlight the importance of focusing on self-efficacy beliefs as an intervention strategy to improve self-efficacy and HRQL in adolescents involved in bullying.

In [7] in 2018, the authors presented that girls and adolescents aged 17-18 years presented significantly higher psychosomatic symptoms, both groups also scored worse in all dimensions of HRQL, although only the dimensions related to physical wellbeing, mental well-being and mood and stress reached significance. All psychosomatic symptoms were inversely associated with the 10 dimensions of the KIDSCREEN-52. The regression models performed showed that sadness, difficulty concentrating and difficulty sleeping were the predictors of the worst HRQL in both sexes and age groups, and these variables explained between $30 \%$ and $41 \%$ of the variance in the HRQL of adolescents. In conclusion, psychosomatic symptoms are more frequent in girls and older adolescents, and predictors of worse HRQL. It is important to differentiate them from medical conditions to avoid unnecessary interventions. As expressions of emotional distress, they must be evaluated and treated comprehensively because they interfere with daily life and increase the vulnerability of adolescence.

The general objective of the study is to determine the healthrelated quality of life in students of an educational institution. To do this, reviewing various studies verifies that there is no research on this area, neither from this population that currently has problems most of them in the psychological field. In the review of national and international scientific literature, it is evident that there are few scientific researches that use the KIDSCREEN 52 in their work on health-related quality of life, and it is evident that most of the researchers are international. In Callao, and specifically in the place where the research work is carried out, there is no evidence of other research on this topic, which is why this research wants to fill the knowledge gap.

The technique used is the survey. The data collection instrument was the KIDSCREEN 52, which consists of 52 items distributed in its ten dimensions (physical well-being, psychological well-being, mood, self-perception, autonomy, relationship with parents, financial resources, friends and social support, social environment and social acceptance). After completing the field work, the data was entered into a matrix in Microsoft Excel 2016, and then exported to the IBM SPSS Statistics Base 23.0 statistical package, in which the mainly descriptive analysis was performed.

\section{Methodology}

\subsection{Population and sample}

In the present study, it worked with the total population $(\mathrm{N}=728)$, which is made up of adolescents between 12 and 18 years old of the 2019 school year from a public school in the Ventanilla district, the 21 classrooms have around 700 students, each participant was selected according to the inclusion and exclusion criteria of the study; in addition, each participant was informed about the objectives and scope of the study, and then invited to bring the corresponding informed consent and assent signed.

Table 1: Distribution of classrooms at the secondary level of the Jorge Portocarrero Rebaza educational institution

\begin{tabular}{|l|l|l|l|}
\hline Grade & Shifts & Classrooms & $\begin{array}{l}\text { Total } \\
\text { students }\end{array}$ \\
\hline First & Afternoon & 5 & 164 \\
\hline Second & Afternoon & 5 & 177 \\
\hline Third & Morning & 4 & 162 \\
\hline Fourth & Morning & 4 & 119 \\
\hline Fifth & Morning & 3 & 106 \\
\hline Total & 21 & 728 \\
\hline
\end{tabular}

\subsection{Inclusion and Exclusion Criteria}

Inclusion criteria:

- All students who present the consent of their parents and informed assent by them.

- Students between 8 and 18 years old.

- Students who have attended the day of the survey.

Exclusion criteria:

- Students over 18 years old.

- Students who do not wish to take the survey.

\subsection{Analysis of the variable}

The present study presents Health-related quality of life as the main variable, according to its nature, it is a qualitative variable and its measurement scale is ordinal.

The health-related quality of life (HRQL) corresponds to the perception that people have of their level of subjective well-being, considering various aspects of their lives and their impact on their state of health [2]. It is the perception that high school adolescents of II.EE Jorge Portocarrero Rebaza has about their position in life, in the cultural context and value systems in which they operate and in relation to their objectives, expectations, standards and concerns also, it is expressed by physical well-being, psychological wellbeing, mood, self-perception, autonomy, relationship with parents, financial resources, friends and social support, social environment and social acceptance, which will be measured with the KIDCREEN 52 questionnaire.

The technique used in the study for the data collection process was the survey, this technique contemplates a set of standardized procedures that wants to obtain a significant amount of data quickly and efficiently. 
Regarding the data collection instrument that allowed to measure the main variable Health-related quality of life, the KIDSCREEN 52 questionnaire was used. It is financed by the European Commission within the "Quality of life and management of living resources" Fifth Framework Programmed (QLC-CT2000-00751) and was held for 3 years; they are a group of instruments developed and standardized for the topography of Health-related quality of life (HRQL - Health related to quality of life), in children and adolescents aged 8 to 18 years [8].

The KIDSCREEN-52 tool was developed jointly by 13 European countries, including Spain, following a simultaneous intercultural protocol. This ensures that future comparisons can be made between different countries. Later it has been adapted to different countries in Latin America, such as Venezuela and Argentina. The instrument was constructed using psychometric studies based on classical test theory and more advanced models, such as Item Response Theory (IRT). Based on the KIDSCREEN implementations, a computer-adaptive trial version was also developed using an IRT-based methodology. The original Spanish version of the KIDSCREEN-52 (KIDSCREEN-52-ES) was culturally adapted according to the International Test Commission (ITC) guidelines. We carry out the adaptation following the instructions of the KIDSCREEN Group. There were two stages: First, an adjusted linguistic validation of the instrument was performed. This consisted in the forward and backward translation of the instrument and harmonization until obtaining a semantic and conceptually equivalent version to the original. To maintain the validity of the content of the instrument, the items had to be formulated and expressed in an acceptable and culturally relevant way for Colombian children and adolescents. Subsequently, a pilot study was conducted to examine the validity of the instrument and correct any content or format errors [9].

This instrument is made up of 52 main items which are distributed in 10 dimensions, being these:

Physical well-being: This dimension measures the physical activity of the person, the sensation of energy and everything about the physical part of the person.

- High: Indicates that the participant performs well in physical activities and maintains an adequate physical level.

- Medium: Indicates that the participant alternately performs physical activities but also maintains a good level of physical well-being.

- Low: Indicates that the participant performs minimal physical activities.

Psychological well-being: In this dimension, the person's emotions and satisfaction with life are measured.

- High: Indicates that the participant has their emotions in constant control.

- Medium: Indicates that the person may at times be unable to control their emotions.

- Low: Indicates that the person cannot control their emotions when faced with any situation.

Mood: The level of stress that the person presents and if it presents depressive states are measured.
- High: The person can control and maintain a balance regarding stress.

- Medium: The person may at times not be able to control stress adequately.

- Low: The person may present depressive states due to not being able to adequately control stress.

Self-perception: The perception of its physical appearance and body image and if it feels satisfied with it.

- High: The person appreciates and values their body appearance and feels satisfied.

- Medium: The participant may sometimes not appreciate their body appearance.

- Low: The participant is not satisfied with their image and physical appearance.

Autonomy: Opportunities for activities in their free time are perceived.

- High: The participant has opportunities to do activities in their free time.

- Medium: The participant has some opportunities for activities in their free time.

- Low: The participant has few opportunities to do activities in their free time.

Relationship with parents: The family atmosphere is perceived.

- High: The participant has a very good family relationship.

- Medium: Presents a medium family atmosphere, there may be some problems between family members.

- Low: It presents a bad family atmosphere.

Economic resources: The perception of the family's financial capacity is measured.

- High: Presents adequate family financial capacity to meet the family's needs.

- Medium: Presents an adjusted family financial capacity but still satisfies the basic expenses of the family.

- Low: Presents an adjusted financial capacity.

Friends and social support: The relationship with classmates and/or friends is measured.

- High: Good relationship with classmates.

- Medium: Good relationship with some classmates.

- Low: Bad relationship with classmates.

Social environment: The perception of the ability to concentrate and cognition is measured, in addition to feelings about school.

- High: The participant presents a good concentration and cognition within the school.

- Medium: Presents a regular cognition within the school. 
- Low: The participant does not show adequate concentration and cognition in school.

Social acceptance: Measures the feeling of rejection from friend or people around.

- High: The participant does not present any rejection from its colleagues.

- Medium: Presents some rejection of its colleagues.

- Low: Presents rejection by their peers, the participant suffers from bulling by their peers.

\section{Reliability of the KIDSCREEN 52 data collection instrument}

The reliability of the instrument was determined based on the Cronbach's alpha statistic, which presents an internal consistency index of $0.885(\alpha>0.6)$. Therefore, a high level of general reliability of the instrument is identified.

\begin{tabular}{llr}
\hline Reliability & Cronbach's alpha & 0,885 \\
& No. of elements & 52 \\
\hline
\end{tabular}

\section{Validity of the data collection instrument Health-related quality of life KIDSCREEN 52}

To determine the validity of the instrument, the Kaiser-MeyerOlkin (KMO) sample adequacy index and the Barttlet sphericity test were used. After the analysis, a sample adequacy coefficient of 0.928 and a significance value of 0.000 ( $\mathrm{x} 2=20481.828$; g.l. $=$ 1326; $\mathrm{p}<0.05$ ) were obtained in the Barttlet sphericity test. Given the above data, an acceptable validity of the instrument can be identified.

\begin{tabular}{|c|c|c|c|}
\hline \multirow{5}{*}{$\begin{array}{l}\text { Valid } \\
\text { ity }\end{array}$} & \multicolumn{2}{|c|}{$\begin{array}{l}\text { Measure of sampling adequacy of } \\
\text { Kaiser-Meyer-Olkin }\end{array}$} & 0,928 \\
\hline & \multirow{4}{*}{$\begin{array}{l}\text { Bartlett's test of } \\
\text { sphericity }\end{array}$} & $\mathrm{X}^{2}$ & 2048 \\
\hline & & approximate & 1,828 \\
\hline & & $\mathrm{gl}$ & 1326 \\
\hline & & Sig. & 0,000 \\
\hline
\end{tabular}

\subsection{Data Collection}

\section{Authorization and prior coordination for data collection}

In order to start the data collection process, steps were taken to access the institution where the field work will be carried out.

At first during the month of September of the year 2019, a request letter of introduction to the Professional School of Nursing of the Universidad de Ciencias y Humanidades to formally manage the permit and be able to carry out the surveys at the Jorge Portocarrero Rebaza educational institution.

In a second moment, it coordinated with the director of the Jorge Portocarrero Rebaza educational institution, Mr. Rafael Salvador Mimbela, and the importance of the research was explained to him, authorization was requested for the development of the work, to which he agreed.

\section{Application of data collection instrument}

On October $4^{\text {th }}, 2019$, the survey was carried out in the students who attended the educational institution, they were 11 classrooms in the morning shift and 10 classrooms in the afternoon shift with 40 students for each classroom. The time used in each classroom was approximately 25 minutes. In each classroom, an authorization document was requested from the parent or guardian of the adolescent, since the informed consent had to be signed. At the time of the delivery of the questionnaire, each classroom was informed how it should be filled out correctly since they were closed-response questions based on marking with an " $\mathrm{X}$ " in each question, the students were clarified in their doubts having more doubts the students from first years of secondary study. At the conclusion of the data collection procedure, the correct filling and coding of each of the sheets with the instrument was verified. It is important that a professional carry out this type of research, in this case I as a nursing professional went to explain the correct filling of the questionnaire since nursing is prepared in all areas of health such as the psychological area among others and therefore prepared for any doubt of the group of questions presented by each dimension of the instrument. As the reader can see in the Figure 1, it shows the application of the survey in the Education Institution.

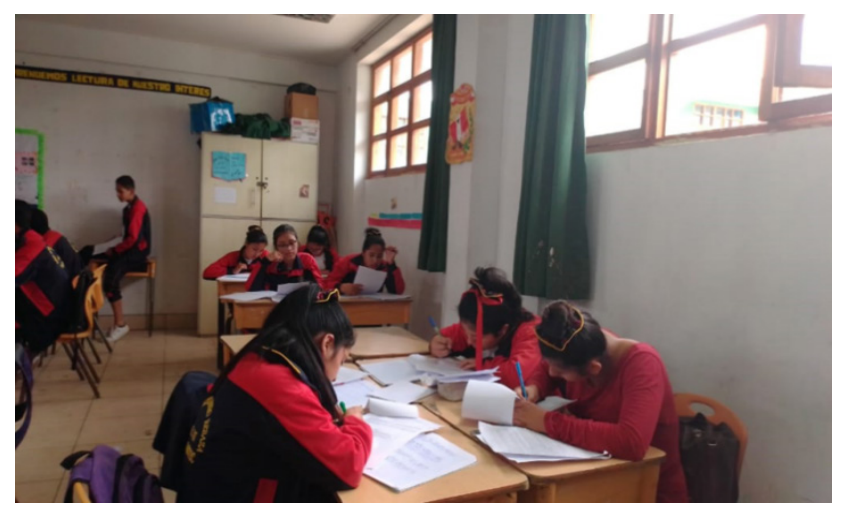

Figure 1: Application of the surveys in the Educational Institution

\subsection{Statistical analysis methods}

At the end of the data collection process, a matrix prepared in the Microsoft Excel spreadsheet will be entered, then these will be exported to the statistical program IBM SPSS Statistics Base 23.0, it will proceed to its corresponding analysis. As it is a descriptive design research, the methods of descriptive statistics will be used for data analysis; where the tables of absolute and relative frequencies will be used, the measures of central tendency, among other tests for the analysis of the sociodemographic information, also corresponding to the variables and dimensions involved. Finally, tables and graphs will be obtained according to the sociodemographic data, general and specific objectives of the study; for later description and discussion.

\section{Results}

Below are three summary tables; the first will show the demographic data of the students who participated in the study, the second table shows the result of the variable Quality of life related to health, and the third table shows the results of each dimension. 
Table 2: Sociodemographic data in students of an Educational Institution of Ventanilla $(\mathrm{N}=728)$

\begin{tabular}{|c|c|c|}
\hline Age & $\begin{array}{l}\text { Minimum } \\
\text { Maximum }\end{array}$ & Media (D.T.) \\
\hline & $12-18$ & $14.06( \pm 1.505)$ \\
\hline Sex & Frequency (f) & Percentage (\%) \\
\hline Female & 357 & 49.0 \\
\hline Male & 371 & 51.0 \\
\hline $\begin{array}{l}\text { Degree of the } \\
\text { interviewee }\end{array}$ & Frequency (f) & Percentage (\%) \\
\hline First high school & 164 & 22.5 \\
\hline $\begin{array}{l}\text { Second high } \\
\text { school }\end{array}$ & 177 & 24.3 \\
\hline $\begin{array}{l}\text { Third high } \\
\text { school }\end{array}$ & 162 & 22.3 \\
\hline $\begin{array}{l}\text { Fourth high } \\
\text { school }\end{array}$ & 119 & 16.3 \\
\hline $\begin{array}{l}\text { Fifth high } \\
\text { school }\end{array}$ & 106 & 14.6 \\
\hline Study shift & Frequency (f) & Percentage (\%) \\
\hline Morning & 389 & 53.4 \\
\hline Afternoon & 339 & 46.6 \\
\hline Type of Family & Frequency (f) & Percentage (\%) \\
\hline Nuclear & 424 & 58.2 \\
\hline Single parent & 176 & 24.2 \\
\hline Extended & 33 & 4.5 \\
\hline Expanded & 58 & 8.0 \\
\hline Reconstituted & 26 & 3.6 \\
\hline $\begin{array}{l}\text { Family } \\
\text { equivalent }\end{array}$ & 6 & .8 \\
\hline Single person & 5 & .7 \\
\hline $\begin{array}{l}\text { Disability, } \\
\text { illness or } \\
\text { medical } \\
\text { problem }\end{array}$ & Frequency (f) & Percentage (\%) \\
\hline No & 622 & 85.4 \\
\hline Yes & 106 & 14.6 \\
\hline
\end{tabular}

In Table 2, it has the sociodemographic data of the study participants, a total of 728 students. Regarding the age of the study participants, it was determined that they fluctuate in a range from 12 to 18 years old, with an average of $14.06(+1.505)$ years old. Regarding sex, it was found that $51.0 \%$ are male. Fourth and fifth year of secondary school have the lowest percentages of students with $16.3 \%$ and $14.6 \%$ respectively. The majority of respondents, equivalent to $53.4 \%$, study in the morning shift. $58.2 \%$ of the sample claims to be part of a nuclear family. Only $14.6 \%$ claim to have a disability, difficulty or some medical problem.

Table 3: Health-related Quality of life in adolescents of an Educational Institution of Ventanilla $(\mathrm{N}=728)$

\begin{tabular}{|l|l|l|l|}
\hline \multicolumn{2}{|c|}{} & N & \% \\
\hline \multirow{3}{*}{$\begin{array}{l}\text { Health-related } \\
\text { quality of life }\end{array}$} & Low & 0 & 0.0 \\
\cline { 2 - 4 } & Medium & 298 & 40.9 \\
\cline { 2 - 4 } & High & 430 & 59.1 \\
\hline \multirow{2}{*}{ Total } & 728 & 100 \\
\hline
\end{tabular}

In Table 3, it can see the health-related quality of life in adolescents of an Educational Institution of Ventanilla, where 430 students representing $59.1 \%$ have high quality of life and 298 students representing $40.9 \%$ have medium quality of life.

Table 4: Health-related Quality of life according to its dimensions, in adolescents of an Educational Institution of Ventanilla $(\mathrm{N}=728)$

\begin{tabular}{|c|c|c|c|}
\hline & & $\mathbf{N}$ & $\%$ \\
\hline \multirow{3}{*}{$\begin{array}{l}\text { Physical well- } \\
\text { being }\end{array}$} & Low & 23 & 3.2 \\
\hline & Medium & 360 & 49.5 \\
\hline & High & 345 & 47.4 \\
\hline \multirow{3}{*}{$\begin{array}{l}\text { Psychological } \\
\text { well-being }\end{array}$} & Low & 6 & 0.8 \\
\hline & Medium & 239 & 32.8 \\
\hline & High & 483 & 66.3 \\
\hline \multirow{3}{*}{ Mood } & Low & 25 & 3.4 \\
\hline & Medium & 219 & 30.1 \\
\hline & High & 484 & 66.5 \\
\hline \multirow{3}{*}{ Self-perception } & Low & 7 & 1.0 \\
\hline & Medium & 260 & 35.7 \\
\hline & High & 461 & 63.3 \\
\hline \multirow{3}{*}{ Autonomy } & Low & 27 & 3.7 \\
\hline & Medium & 333 & 45.7 \\
\hline & High & 368 & 50.5 \\
\hline \multirow{3}{*}{$\begin{array}{l}\text { Relationship } \\
\text { with parents }\end{array}$} & Low & 25 & 3.4 \\
\hline & Medium & 267 & 36.7 \\
\hline & High & 436 & 59.9 \\
\hline \multirow{3}{*}{$\begin{array}{l}\text { Economic } \\
\text { resources }\end{array}$} & Low & 64 & 8.8 \\
\hline & Medium & 400 & 54.9 \\
\hline & High & 264 & 36.3 \\
\hline \multirow{3}{*}{$\begin{array}{l}\text { Friends and } \\
\text { social support }\end{array}$} & Low & 14 & 1.9 \\
\hline & Medium & 254 & 34.9 \\
\hline & High & 460 & 63.2 \\
\hline \multirow{3}{*}{$\begin{array}{l}\text { Social } \\
\text { environment }\end{array}$} & Low & 18 & 2.5 \\
\hline & Medium & 321 & 44.1 \\
\hline & High & 389 & 53.4 \\
\hline \multirow{3}{*}{$\begin{array}{l}\text { Social } \\
\text { acceptance }\end{array}$} & Low & 18 & 2.5 \\
\hline & Medium & 166 & 22.8 \\
\hline & High & 544 & 74.7 \\
\hline
\end{tabular}

In Table 4, it can see the Health-related quality of life according to its dimensions in adolescents of an Educational Institution of Ventanilla, where the most affected dimension was that of economic resources with 64 students representing $8.8 \%$ having a level low. In the physical well-being dimension, it is noted that it presents a medium quality of life with a percentage 
of $49.5 \%$, giving an idea that adolescents from that educational center practice physical activity both inside and outside the educational institution. In the psychological well-being dimension, it is noted that they present a high quality of life of $66.3 \%$, revealing that adolescents from the educational institution present emotions where they prioritize the positive ones and satisfaction with life. In the mood dimension, it is noted that it presents a high level with a total of $66.5 \%$, thus expressing that the students present a balanced level of stress. In the self-perception dimension, it can observe that it presents a result of $63.3 \%$; which corresponds to a high level, demonstrating that students have a good perception of their body image and physical appearance. In the autonomy dimension, it is noted that it presents a high level with a percentage of $50.5 \%$ showing that the educational institution does allow them to have time for their activities in their free time. In the relationship with parents' dimension, it appreciates that $3.4 \%$ of students do not have a good family atmosphere since they do not live with their parents, but with uncles and/or grandparents. In the economic resources dimension, it is noted that they present a medium level with a percentage of $54.9 \%$, reflecting that the financial capacity of the parents is not low but that it does not cover the maximum with respect to the expenses of the students, since it was observed that most students have one or more siblings studying in lower grades. Regarding the friends and social support dimension, it presents a high level with a total of $63.2 \%$, reflecting that the students have good communication with their classmates or friends who do not study with them. In the social environment dimension, it reflects a high level with a total of $53.4 \%$, which shows a good feeling about school, also a good ability to concentrate and a positive feeling about school. Finally, in the social acceptance dimension, it is observed that a total of $2.5 \%$ presents a low level, reflecting that in the educational institution there are some students who express rejection of their peers.

\section{Discussion}

In the following study, the issue of health-related quality of life is raised from the point of view of promoting adolescent health, which wants to contribute to educational institutions which are part of adolescent educational training, which must include programs that allow adolescents to enhance their ability to interrelate and adequately shape their personality.

The participants in this study were high school students from a public school in the province of Callao, who had an average age of 14 years, from a lower-middle socioeconomic level in the district where the school is located, who mostly belonged to a nuclear family. Most of the students in this study did not have any significant physical disabilities, illnesses, or medical problems.

At a general level, it was found that the students who participated in this study had high levels of HRQL, this because they were very clear about their personal goals and objectives, optimistically seeing their future, as in other studies on the same subject, such as the study of Hidalgo et al [1], in this study it is evident that the present one focuses on school adolescents, which results in a low level HRQL since the students affirmed that they presented bullying among their classmates, thus demonstrating a Health-related quality of life from medium to low, therefore it is asked to delve into the dimensions that present difficulties.
Compared to other studies, this research only worked with the variable Health-related quality of life since the instrument used focuses directly on that variable and the type of population, therefore the KIDSCREEN 52 compared to its two existing types, holistically assesses the age group of people who carried out the research work.

The research work wants to demonstrate the related quality of life in adolescents since in these times, that group of people present problems most of them in the psychological part. In the following research work, it wants to demonstrate that the adolescent is a holistic person and therefore it must be studied in all its dimensions; In this study group, it verified that the educational institution presents few problems due to the result found that was between a medium and high level with respect to the variable Health-related quality of life.

\section{Conclusions}

It is concluded that the Health-related quality of life is the set of manifestations that a person presents most of them in the subjective part (emotions, sensations, among others); this is influenced by the state of health that is presented at the time; this already gives an idea of how the adolescent feels at the school stage. In this case, what we are looking for with this study is to give us an idea of how the adolescent feels at that moment.

It is concluded that the educational institution, the director provided the support for the realization of the survey and later the processing of the information given by the study population. The study was also successfully carried out thanks to the teachers of the institution since they offered class time and especially to the students who were the study population, since they were predisposed to collaborate with the study.

As a future research work, other health professionals are expected to carry out research work in localities where populations are vulnerable, such as the case of Pachacutec-Ventanilla; since other research could be carried out with other groups of people and thus obtain relevant results to complement the improvement of the Peruvian population.

\section{Conflicts of Interest}

The authors declare no conflict of interest.

\section{References}

[1] C. Hidalgo, T. Molina, R. Molina, R. Sepúlveda, V. Martínez, Montaño, Bullying y calidad de vida relacionada con la salud en adolescentes escolares

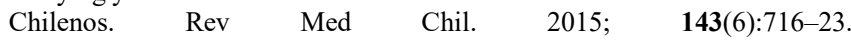
http://dx.doi.org/10.4067/S0034-98872015000600004

[2] E. González et al., "Diferencias de género en la calidad de vida relacionada con la salud en adolescentes escolarizados chilenos Gender differences in health-related quality of life of Chilean adolescent students. Rev Med Chil. 2016; 144(3):298-306. http://dx.doi.org/10.4067/S003498872016000300004

[3] L. Rajmil, "Advances and challenges in the measurement of health related quality of life in the child and adolescent population. An Pediatr [Internet]. 2019; 90(5) :261-2.: https://doi.org/10.1016/j.anpedi.2019.01.011

[4] I. Bica , J. Costa, "Original Article Sociodemographic infl uence in healthrelated quality of life in adolescents. Acta Paul Enferm. 2020;33:1-7. https://doi.org/10.37689/acta-ape/2020ao0054

[5] F. Vilugrón, C.A. Hidalgo et al., "Uso de sustancias psicoactivas y calidad de vida relacionada con la salud en adolescentes escolarizados. Rev Med Chil. 2017; 145(12):1525-34. http://dx.doi.org/10.4067/s003498872017001201525

[6] K. Haraldstad et al., "Associations between self-efficacy, bullying and 971 
health-related quality of life in a school sample of adolescents: a crosssectional study. BMC Public Health. 2019; 19(1):1-9. https://doi.org/10.1186/s12889-019-7115-4

[7] R.M. Fuentes-Chacón et al., "Psychosomatic symptoms as an expression of the deterioration of the health-related quality of life in adolescents. Aten Primaria. 2018; 50(8):493-9. doi: 10.1016/j.aprim.2017.06.009

[8] KIDSCREEN-52 - kidscreen.org [Internet]. Available from: https://www.kidscreen.org/español/cuestionario-kidscreen/kidscreen-52/

[9] J. Valencia, P. Galvañ, C. Martínez, C. García, R. Martínez. Adjusted linguistic validation and psychometric properties of the Colombian version of KIDSCREEN-52. J Child Heal Care. 2019; 23(1):20-34. https://doi.org/10.1177/1367493518777291 